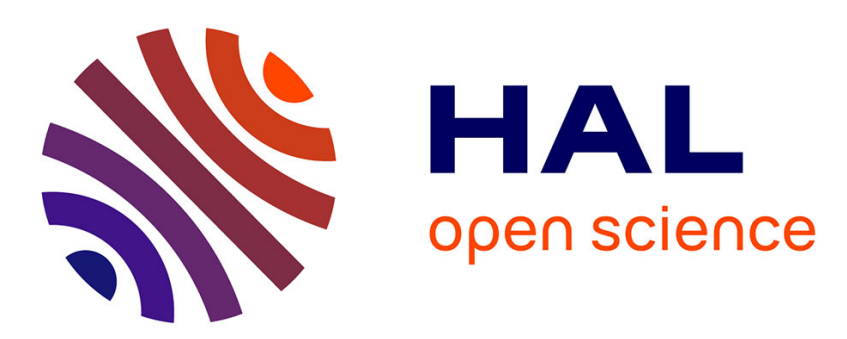

\title{
Affinement du concept de la protéine idéale pour le porc en croissance
}

\author{
Y. Henry
}

\section{To cite this version:}

Y. Henry. Affinement du concept de la protéine idéale pour le porc en croissance. Productions Animales, 1993, 6 (3), pp.199-212. hal-00896054

\section{HAL Id: hal-00896054 https://hal.science/hal-00896054}

Submitted on 1 Jan 1993

HAL is a multi-disciplinary open access archive for the deposit and dissemination of scientific research documents, whether they are published or not. The documents may come from teaching and research institutions in France or abroad, or from public or private research centers.
L'archive ouverte pluridisciplinaire HAL, est destinée au dépôt et à la diffusion de documents scientifiques de niveau recherche, publiés ou non, émanant des établissements d'enseignement et de recherche français ou étrangers, des laboratoires publics ou privés. 
INRA Prod. Anim.,

1993, 6 (3), $199-212$.

\section{Y. HENRY}

INRA Station de Recherches Porcines 35590 St-Gilles

\section{Affinement du concept de la protéine idéale pour le porc en croissance}

En dehors de l'économie de protéines et de la réduction des rejets azotés, l'amélioration de l'équilibre en acides aminés du régime alimentaire chez le porc a un impact bénéfique sur l'appétit et les performances de croissance. Le besoin en lysine a été beaucoup étudié du fait que c'est en général l'acide aminé le plus limitant des aliments pour les porcs. Mais, à la différence de la lysine qui intervient peu dans les processus métaboliques, les interactions entre les autres acides aminés sont à considérer et rendent plus complexe le calcul des quantités à apporter et l'équilibre à respecter dans les aliments.

Beaucoup a été dit et écrit à propos de la protéine dite "idéale", ou équilibrée, dans l'alimentation du porc, notamment pour la croissance. Comme nous avons eu l'occasion de le souligner précédemment (Henry 1988, Sève

\section{Résumé}

Cet article traite des données récentes sur les relations d'équilibre entre les acides aminés dans l'alimentation du porc en croissance, au travers du concept de la protéine "idéale". Après avoir précisé les limites de ce concept, sur le plan de la constance des rapports entre les teneurs en acides aminés indispensables et celle en lysine, prise comme référence, sont considérés les ratios entre les acides aminés limitants secondaires (tryptophane, thréonine, méthionine et acides aminés soufrés) et la lysine, compte tenu des spécificités de leur rôle fonctionnel au plan métabolique et physiologique. Pour cela, l'incidence des écarts entre le profil de composition en acides aminés de la protéine alimentaire et celui de la protéine idéale (excès de protéines) sur l'ingestion alimentaire et les performances de croissance est étudiée selon la nature de l'acide aminé le plus limitant.

En raison de sa faible contribution aux processus métaboliques autres que ceux concernant la synthèse de protéines corporelles, la lysine constitue une référence stable pour l'expression des rapports entre les acides aminés. A la différence de la lysine, le tryptophane interagit fortement et négativement avec les protéines excédentaires (acides aminés neutres de grande taille) au niveau de l'appétit et de la croissance, en liaison avec un dysfonctionnement du système sérotoninergique. Ceci met en défaut la constance du rapport tryptophane / lysine, qui devrait être corrigé sur la base d'un ratio minimum tryptophane / acides aminés neutres de $4 \%$, pour se prémunir d'un risque d'excès de ces derniers dans certaines protéines alimentaires. Dans le cas de la thréonine, lorsqu'elle est limitante, il ressort une interaction positive avec les acides aminés non indispensables (acide glutamique). L'équilibre méthionine / cystine a été reconsidéré en fonction des données récentes de la bibliographie. En conclusion, les recommandations concernant les rapports acides aminés / lysine pour le porc en croissance ont été réactualisées.
1988, Henry et Sève 1993b), l'idée de la protéine idéale, initialement l'oeuvre de Mitchell (1964), a été reprise plus récemment, et pour la première fois dans le cas du porc, par les chercheurs britanniques (Cole 1979, 1980, ARC 1981). Ces derniers considéraient que les variations des besoins en acides aminés entre les différentes catégories de porcs correspondaient simplement à des différences dans les quantités d'une protéine apportant les acides aminés indispensables (AAI) suivant des proportions constantes et suffisamment d'azote aminé pour la synthèse des acides aminés non indispensables (AANI). La protéine idéale, qui s'explique par une certaine homéostasie de la composition en acides aminés des tissus formés (protéines corporelles, comme le muscle, ou exportées, comme le lait), présente ainsi un profil défini de composition en AAI (en pourcentage de la protéine ou / $16 \mathrm{~g}$ d'N, ou sous forme de rapports entre les AAI). En même temps, le rapport entre la somme des AAI et celle des AANI est sensiblement égal à l'unité $(0,45$ et 0,55 respectivement pour les AAI et les AANI, selon Wang et Fuller 1989 ; rapport optimum $\mathrm{N}$ indispensable / $\mathrm{N}$ non indispensable de 0,96, selon Chung et Baker 1991). Sur le plan pratique, compte tenu du rôle particulier de la lysine comme acide aminé limitant de la plupart des régimes consommés par le porc, les relations d'équilibre entre les acides aminés indispensables sont traduites en rapportant les besoins pour chacun d'entre d'eux à celui de la lysine. De plus, cette façon 
d'opérer fait abstraction de la notion encore imprécise d'acides aminés indispensables et non indispensables.

En réalité, dans les conditions habituelles d'alimentation du porc, les protéines ingérées présentent un profil de composition en acides aminés qui s'écartent plus ou moins fortement de celui de la protéine idéale. Les régimes issus de la formulation sont naturellement déséquilibrés en acides aminés, avec un excès de protéines par rapport à l'acide aminé le plus limitant (en l'occurrence la lysine), puisque le taux global de protéines est simplement ajusté pour couvrir le besoin en cet acide aminé limitant. Mais, l'acide aminé limitant primaire peut ne pas être celui prévu lors de la formulation. Il en est ainsi lorsque la disponibilité (digestibilité iléale) d'un ou plusieurs acides aminés est plus faible que les valeurs choisies initialement au moment de la formulation, faisant alors apparaître, avant la lysine, une déficience en l'un ou l'autre des acides aminés limitants secondaires a priori, au vu de la seule composition (thréonine, méthionine ou tryptophane). En conséquence, l'influence d'un excès global de protéines dans l'alimentation du porc peut être considérée comme étant la résultante d'un déséquilibre entre les acides aminés les moins limitants (acides aminés ramifiés et aromatiques, arginine), qui sont en excès par rapport aux besoins, et les plus limitants (lysine, acides aminés soufrés, thréonine, tryptophane), selon leur ordre dans l'excès ou le déficit. Ces excès inévitables de certains acides aminés par rapport à d'autres ne sont pas sans constituer un risque pour l'expression optimale des performances de production. Plus particulièrement, des déséquilibres entre acides aminés peuvent avoir, par le biais des fluctuations des teneurs en ces composés dans les compartiments sanguin et cérébral qu'elles engendrent, des effets spécifiques sur l'appétit, et par voie de conséquence sur les performances de croissance. C'est la raison pour laquelle il nous a paru important de raisonner l'équilibre en acides aminés, non pas sous l'angle d'une protéine idéale fictivement et passivement intégrée dans une protéine alimentaire déséquilibrée, mais en considérant l'incidence des écarts par rapport à l'équilibre sur les performances des animaux, par la prise en compte des acides aminés en excès selon leur nature (proportions respectives des AAI et AANI dans les protéines en excès, équilibre au sein des AANI) et l'acide aminé limitant primaire, selon sa nature. Bien entendu, si ce risque de déséquilibre est réel dans le cas de l'utilisation de régimes complexes, contenant des sources de protéines de nature très diverse comme les produits de substitution des céréales (PSC), il l'est moins si l'on a recours à des associations alimentaires simplifiées, du type céréales - tourteau de soja. Il est connu que le modèle maïs - soja américain apporte une grande sécurité quant à l'équilibre en acides aminés du régime, mais il est aussi risqué de conclure, à partir de ce modèle, que les problèmes de déséquilibre en acides aminés dans l'alimentation du porc ne se posent pas.

Dans une première partie, il s'agira de relativiser le concept de la protéine idéale en fonc- tion des acquisitions récentes sur le sujet. L'essentiel de l'article est ensuite consacré à la signification des ratios acides aminés / lysine. Pour cela, après avoir souligné la stabilité de la lysine comme acide aminé de référence, la spécificité des relations d'équilibre entre les principaux acides aminés limitants secondaires (tryptophane, thréonine, méthionine et acides aminés soufrés) et la lysine, sera étudiée selon le profil de composition du régime en acides aminés.

\section{1 / Relativité du concept de la "protéine idéale"}

La protéine idéale pour la croissance du porc est caractérisée par un profil défini de composition en acides aminés indispensables, en pourcentage de la protéine (ou en $\mathrm{g} / 16 \mathrm{~g}$ N). Initialement proposée par l'ARC (1981), sa composition a fait l'objet par la suite d'une réactualisation, sur la base d'une expérimentation, par Wang et Fuller (1989). Un moyen commode de décrire cette protéine idéale est de retenir le pourcentage de lysine dans la protéine (qui s'est abaissé de 7,0 à $6,5 \%$ ) et le ratio de chacun des autres acides aminés indispensables relativement à la lysine (tableau 1). Il convient de préciser que chez le porc on a l'habitude d'inclure, dans les acides aminés dits indispensables, les acides aminés semi-indispensables (cystine, tyrosine), ainsi que l'arginine, ces derniers étant nécessaires pour sa croissance.

Le profil de composition de la protéine idéale est globalement le reflet de la composition en acides aminés des protéines fixées dans l'organisme ou exportées (lait,...). On observe ainsi, chez le porc en croissance, une certaine correspondance entre les teneurs en acides aminés dans la protéine idéale et celles de l'organisme entier (figure 1). Bien entendu, cette correspondance n'est pas parfaite, étant donné que les besoins en acides aminés ne dépendent pas seulement des quantitées fixées mais aussi

Tableau 1. Composition de la protéine idéale en acides aminés pour la croissance du porc.

\begin{tabular}{|lcc|}
\hline $\begin{array}{l}\text { Acides aminés } \\
(\mathrm{g} / 16 \mathrm{~g} \mathrm{~N})\end{array}$ & $\begin{array}{c}\text { ARC } \\
(1981)\end{array}$ & $\begin{array}{c}\text { Wang et Fuller } \\
(1989)\end{array}$ \\
\hline Lysine & $7,0(1,00)$ & $6,5(1,00)$ \\
Méthionine + cystine & $3,5(0,50)$ & $4,1(0,63)$ \\
Thréonine & $4,2(0,60)$ & $4,7(0,72)$ \\
Tryptophane & $1,0(0,14)$ & $1,2(0,18)$ \\
Isoleucine & $3,8(0,54)$ & $3,9(0,60)$ \\
Leucine & $7,0(1,00)$ & $7,2(1,10)$ \\
Valine & $4,9(1,07)$ & $4,9(0,75)$ \\
Histidine & $2,3(0,33)$ & - \\
Phénylalanine+ tyrosine & $6,7(0,96)$ & $7,8(1,20)$ \\
\hline
\end{tabular}

Les valeurs relatives sont indiquées entre parenthèses. Les besoins en arginine (pour les deux références) et en histidine (pour la deuxième référence) n'ont pas été déterminés. 
Figure 1. Profils de composition en acides aminés de la protéine idéale (selon Fuller 1991) et des protéines déposées dans l'organisme du porc en croissance (selon Batterham et al 1990).

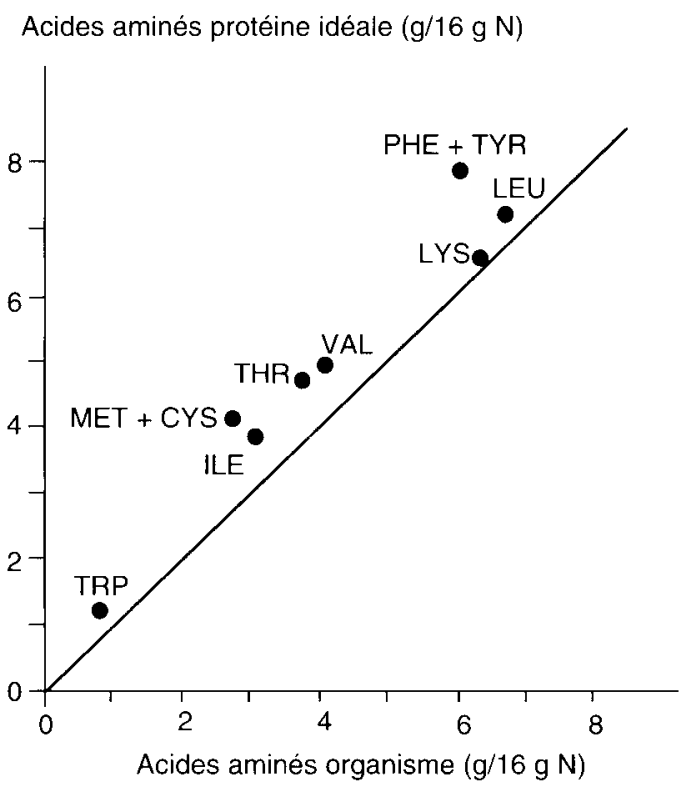

de l'efficacité de leur utilisation pour la formation des dépôts corporels, variable selon leurs particularités métaboliques (Sève et Ballèvre 1991). En outre, les teneurs en acides aminés des protéines déposées sont susceptibles de varier en fonction à la fois des modifications de leur distribution entre les différents compartiments corporels et des différences et fluctuations de composition des protéines en acides aminés d'un compartiment à l'autre : il en est ainsi en fonction de l'âge.et du stade physiologique (jeune animal, porc en croissance-finition, truie adulte), et du niveau de production. Quoi qu'il en soit, au niveau de l'organisme entier on constate une certaine atténuation de ces variations, de sorte que sur l'ensemble de la croissance le profil de composition en acides aminés des protéines fixées peut être considéré comme étant relativement constant : de l'ordre de 6,5 à $7 \%$ de lysine dans les protéines du corps entier, soit une valeur comparable à celle de la protéine idéale. Par contre, pour ce qui concerne les acides aminés participant activement à d'autres métabolismes que la synthèse de protéines corporelles (méthionine, tryptophane), les ratios relativement à la lysine sont plus élevés au niveau du besoin que dans les protéines fixées. Comme le faisait remarquer Sève (1988), la "protéine idéale expérimentale", destinée à assurer la couverture des besoins en acides aminés, se distingue assez nettement de la "protéine idéale corporelle".

On pourrait s'étonner que l'on ait priviligié le concept de la protéine idéale dans le cas du porc, et notamment pour la croissance. Si l'on compare différentes espèces animales, en particulier parmi les monogastriques (figure 2), on peut observer une certaine similitude dans le profil de composition en acides aminés des protéines formées, et d'une manière encore plus fine si l'on rapproche les animaux producteurs

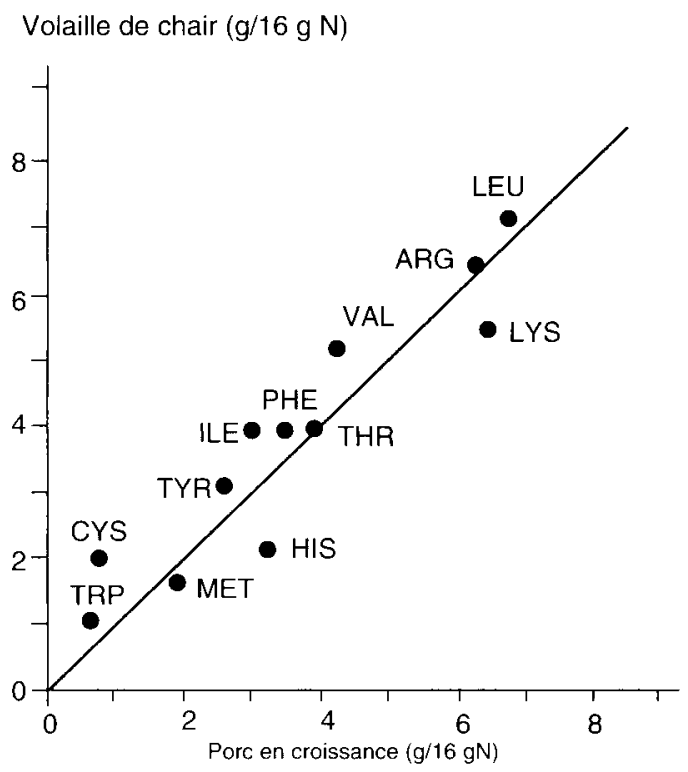

Figure 2.

Profils de composition en acides aminés des protéines déposées dans l'organisme entier du porc en croissance (Batterham et al 1990) en comparaison avec les volailles de chair (Fisher 1983), et dans le lait de truie (Dourmad et al 1991) en comparaison avec l'oeuf de poule (Fisher 1983).

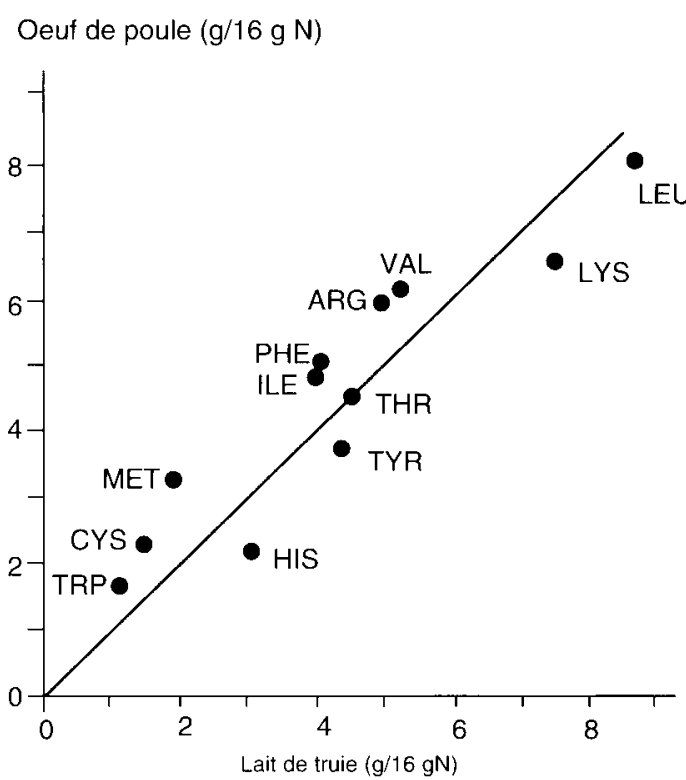

de viande (porc, volailles de chair) ou ceux exportant des protéines sous forme de lait (truie) ou d'oeufs (poule). Néanmoins, la teneur en lysine des protéines de l'organisme apparaît plus élevée chez le porc que chez les volailles de chair, tandis que pour ces dernières les teneurs en cystine (emplumement) et en tryptophane sont plus fortes. Les protéines de lait et d'oeuf entier sont dans l'ensemble plus riches en acides aminés indispensables (respectivement 55 et $51 \%$ ) que les protéines corporelles ( 46 et $43 \%$ pour les volailles de chair et le porc). Les protéines de lait semblent mieux pourvues en lysine que les protéines d'oeuf, qui renferment des teneurs plus élevées pour la plupart des autres acides aminés indispensables.

Il n'est pas surprenant qu'une contribution importante de certains acides aminés aux processus métaboliques conduit à une différenciation du profil de composition de la protéine idéale pour l'entretien et la croissance propre-
La composition de la protéine idéale reflète celle des protéines fixées dans l'organisme ou exportées. La comparaison de différentes espèces montre une certaine similitude de composition en acides aminés des animaux producteurs de viande et des protéines exportées (lait, oeuf). 
ment dite (ou accrétion protéique). Ceci a été confirmé par Fuller et al (1989), Fuller (1991), qui ont défini les besoins en acides aminés indispensables pour l'entretien et la croissance (tableau 2). Relativement à la lysine, les besoins en méthionine + cystine, thréonine et tryptophane pour l'entretien sont ainsi respectivement de 1,47 - 1,39 et 0,32 contre respectivement $0,53-0,69$ et 0,18 pour l'accrétion protéique. Il s'ensuit que la composition de la protéine idéale n'est pas unique et dépend du niveau de production relativement à l'entretien. Pour un état physiologique proche de l'entretien, comme chez la truie en gestation, les besoins en acides aminés soufrés, thréonine et tryptophane, relativement à la lysine sont ainsi plus élevés que pour le porc en croissance. Il en est de même, quoiqu'à un degré moindre, lorsque le porc en croissance avance en âge et augmente de poids.

Par ailleurs, la signification des rapports acides aminés / lysine dépend du mode d'expression des besoins, que ce soit en quantités brutes ou digestibles. La composition en acides aminés de la protéine idéale, telle qu'elle a été définie par Fuller et al (1989), se rapporte à des régimes semi-purifiés (à base de caséine très digestible et contenant des acides aminés sous forme libre), dont la digestibilité des acides aminés est très élevée et proche de $100 \%$, comme l'ont confirmé Chung et Baker (1992d). Dans les conditions normales d'alimentation, les rapports ainsi définis doivent correspondre aux quantités d'acides aminés digestibles. Compte tenu des différences de digestibilité entre les acides aminés, les ratios acides aminés / lysine, en quantités brutes, sont quelque peu différents. Par exemple, la valeur généralement plus faible de la digestibilité de la thréonine relativement à la lysine se traduit par un rapport thréonine / lysine normalement plus élevé lorsqu'il est exprimé en quantités brutes. De la même façon, on peut s'attendre à de légères fluctuations des ratios

Tableau 2. Composition de la protéine idéale pour l'entretien et la croissance du porc (Fuller et al 1989).

\begin{tabular}{|lcc|}
\hline $\begin{array}{l}\text { Acides aminés } \\
\text { (g/16g N) }\end{array}$ & Entretien & Croissance \\
\hline Lysine & $2,27(1,00)$ & $6,81(1,00)$ \\
Méthionine & $0,72(0,32)$ & $1,88(0,28)$ \\
Méthionine+cystine & $3,34(1,47)$ & $3,58(0,53)$ \\
Thréonine & $3,16(1,39)$ & $4,69(0,69)$ \\
Tryptophane & $0,66(0,29)$ & $1,21(0,18)$ \\
Isoleucine & $1,01(0,44)$ & $4,30(0,63)$ \\
Leucine & $1,61(0,71)$ & $7,80(1,15)$ \\
Valine & $1,19(0,52)$ & $5,25(0,77)$ \\
Phénylalanine & $1,43(0,63)$ & $4,11(0,60)$ \\
Phénylalanine+tyrosine & $2,81(1,24)$ & $8,42(1,24)$ \\
Histidine & - & - \\
Arginine & - & - \\
\hline
\end{tabular}

Les valeurs relatives sont indiquées entre parenthèses. Les besoins en histidine et en arginine n'ont pu être déterminés avec la méthode de délétion utilisée par les auteurs. acides aminés / lysine suivant qu'ils sont exprimés sur la base de la digestibilité apparente ou vraie : valeurs un peu plus élevées en digestibilité vraie en comparaison avec la digestibilité apparente (prise en compte des dépenses endogènes et profil de composition en acides aminés vraisemblablement plus proche de celui des protéines corporelles). Ceci montre en tout cas la nécessité d'une cohérence dans la démarche poursuivie pour l'expression des besoins en acides aminés et de leurs relations d'équilibre.

En définitive, le concept de la protéine idéale chez le porc constitue un moyen commode de globaliser le besoin azoté par la prise en compte de rapports fixés entre les acides aminés indispensables et la lysine, prise comme référence. Cependant, il convient de relativiser la constance des rapports acides aminés / lysine, de même que l'unicité de la protéine idéale pour la croissance du porc.

\section{2 / Lysine : une référence stable pour exprimer les ratios entre acides aminés}

Le choix de la lysine comme référence pour exprimer les relations d'équilibre entre les acides aminés indispensables au sein de la protéine équilibrée (idéale) ou non (alimentaire) peut se justifier pour plusieurs raisons. La lysine est généralement l'acide aminé le plus limitant des aliments consommés par le porc : à ce titre, son besoin a été largement étudié et est relativement bien maîtrisé. A côté de sa contribution dominante $\grave{a}$ la formation des dépôts corporels, la lysine participe peu aux processus métaboliques et à l'entretien de I'animal. De ce fait, la quantité de lysine déposée dans les tissus est reliée linéairement à la quantité de lysine ingérée avec une ordonnée à l'origine proche de zéro : ainsi, son efficacité d'utilisation pour le dépôt varie peu en fonction du niveau d'ingestion. Sur un plan pratique, pour que les ratios acides aminés / lysine conservent tout leur sens, en particulier lors de la formulation des aliments, il convient de s'assurer que la teneur en lysine choisie ne soit pas en excès par rapport au besoin, au risque de surestimer les apports des acides aminés limitants secondaires, et donc d'augmenter le coût des supplémentations éventuelles.

Il est rassurant par ailleurs de préciser que la lysine, en tant qu' acide aminé de référence, interagit faiblement avec les protéines en excès, du point de vue de ses effets sur l'ingestion alimentaire et la croissance, ce qui confêre au rapport lysine / protéines une relative indépendance vis-à-vis du taux de protéines luimême. Il a été ainsi montré (Henry et Sève 1991, Henry et al 1992a, tableau 3) que l'apport de protéines excédentaires $(+25 \%$ par rapport à un régime de base suffisamment pourvu en azote non indispensable) en présence d'un apport limitant de lysine est sans conséquence sur la consommation spontanée 
Tableau 3. Influence de la teneur en lysine du régime, et du taux de protéines et leur nature, sur l'ingestion alimentaire et les performances de croissance du porc (Henry et al 1992a)

\begin{tabular}{|l|cc|ccc|}
\hline & \multicolumn{2}{|c|}{ Effet lysine } & \multicolumn{3}{c|}{ Effet du taux et de la source de PB } \\
\hline & RB & + Lysine & RB & Add. Prot. & Add..AANI \\
& $0,55 \%$ & $0,65 \%$ & $13 \%$ & $15,4 \%$ & $15,2 \%$ \\
& Lysine & Lysine & PB & PB & PB \\
Critère & & & & & \\
& & & & & \\
Aliment ingéré $(\mathrm{kg} / \mathrm{j})$ & 3,14 & 3,25 & 3,25 & 3,24 & 3,10 \\
Gain moyen $(g / j)$ & 965 & 1043 & 1037 & 983 & 993 \\
Indice de consommation & 3,26 & 3,12 & 3,14 & 3,31 & 3,13 \\
Coût énergétique du gain: & & & & & \\
Mcal ED/kg & 10,53 & 10,08 & 10,14 & 10,56 & 10,27 \\
& & & $(100)$ & $(104)$ & $(101)$ \\
Mcal EN/kgb & 7,62 & 7,29 & 7,51 & 7,54 & 7,32 \\
& & & $(100)$ & $(100)$ & $(97)$ \\
\hline
\end{tabular}

${ }^{a}$ Résultats entre 42 et $101 \mathrm{~kg}$ de poids vif. $\mathrm{RB}$ : régime de base. 20 animaux (10 femelles et 10 mâles castrés par traitement). Add.Prot. : addition de protéines à $\mathrm{RB}(+25 \%)$ pour un même profil de composition en acides aminés. Add.AANI : addition d'acides aminés non indispensables (acide glutamique) à $\mathrm{RB}(+25 \%$ d'équivalent - protéines brutes). $\mathrm{PB}$ : Protéines brutes ( $\mathrm{N} \times 6,25)$.

${ }^{h}$ Energie nette $(\mathrm{EN})$ calculée à partir de Noblet et al $(1989,1990)$. Les valeurs relatives sont indiquées entre parenthèses.

d'aliment. Seule l'efficacité alimentaire est diminuée en raison d'une dépense énergétique plus élevée pour le catabolisme des acides aminés en excès (Noblet et al 1987), de façon variable selon la composition des protéines excédentaires. Lorsqu'on fait varier séparément les taux de lysine et de protéines dans le régime, on observe ainsi une relative indépendance de leurs effets sur la croissance du porc : effet bénéfique de la lysine sur la croissance musculaire, effet négatif des protéines en excès sur l'utilisation de l'aliment à des fins énergétiques. Inversement, dans les conditions habituelles d'alimentation, où l'élévation du taux de protéines va de pair avec une augmentation du taux de lysine, les effets propres de la "lysine" et des "protéines" se conjuguent pour atteindre un niveau de performances (efficacité alimentaire) qui ne correspond pas tout à fait à l'optimum, et ceci à des degrés probablement différents selon les potentialités de croissance (type génétique).

Le rapport lysine / protéines dans l'alimentation du porc en croissance peut varier de $4,5 \%$ (régimes relativement déséquilibrés, mais apports adéquats en lysine) jusqu'à un maximum se situant aux alentours de 6,5 à $6,8 \%$ (protéine idéale ou parfaitement équilibrée). Cette limite maximale permet d'avoir une idée suffisamment précise sur le taux minimum de protéine équilibrée relativement à la lysine, compatible avec une croissance optimale chez le porc et pour une concentration en énergie du régime appropriée : de l'ordre de 15 fois le besoin en lysine, en terme de disponibilité (éléments digestibles). Ainsi, pour une teneur en lysine de $0,9-1,0 \%$ (phase active de croissance au cours de la période d'engraissement), dans un régime dont la concentration en énergie est adéquate (aux alentours de $3200 \mathrm{kcal}$ $\mathrm{ED}$ ou $2300 \mathrm{kcal} \mathrm{EN} / \mathrm{kg}$ ), le taux minimum de protéines permettant d'assurer une croissance et une efficacité alimentaire optimales serait de l'ordre de $14-15 \%$. Chez le porc en finition, pour un besoin en lysine de $0,7-0,8 \%$, il serait d'environ $12 \%$. Le choix de l'énergie nette pour l'expression du besoin en lysine relativement à l'énergie se justifie ainsi d'autant plus que l'on s'écarte du profil de composition en acides aminés de la protéine idéale. Réciproquement, lorsqu'on se rapproche de la protéine parfaitement équilibrée, il devient possible de raisonner les besoins du porc en acides aminés et en énergie en terme de substrats ou nutriments disponibles pour la croissance.

\section{3 / Tryptophane : interaction avec les protéines excédentaires (AA neutres)}

A la différence de la lysine, le tryptophane est un acide aminé particulièrement actif au plan métabolique, notamment en tant que précurseur de la sérotonine (ou 5-hydroxytryptamine : 5 -HT), qui est impliquée au niveau cérébral dans la régulation centrale de l'ingestion alimentaire (ou appétit), au même titre que plusieurs autres neurotransmetteurs. De plus, les acides aminés neutres de grande taille (AAN), qui regroupent principalement les acides aminés ramifiés (leucine, isoleucine et valine) et aromatiques (phénylalanine et tyrosine), sont maintenant bien connus pour leur antagonisme vis-à-vis du tryptophane (égale-
La lysine intervient peu dans les processus métaboliques. Sa quantité déposée dans les tissus est liée linéairement à la quantité ingérée, jusqu'au niveau de satisfaction du besoin. 
ment un acide aminé neutre), lors de son passage à travers la barrière hémato-encéphalique, puisqu'utilisant le même système de transport de type $\mathrm{L}$, par référence à la leucine (Christensen 1975). Il s'ensuit une interférence au niveau de la synthèse de 5-HT (figure 3 ). En particulier, on peut penser que le rapport TRP / AAN dans l'aliment, puis dans le compartiment sanguin, agit d'une manière spécifique sur l'appétit du porc, dans le cas d'utilisation de régimes à teneur élevée en protéines (et donc en acides aminés neutres).

Cette hypothèse d'interaction négative entre les protéines en excès et le tryptophane a fait l'objet récemment d'une confirmation expérimentale dans le cas du porc (Henry et Sève 1991, Uttecht et al 1991, Henry et al 1992b). Chez le porc alimenté à volonté entre 40 et $100 \mathrm{~kg}$ de poids vif, l'apport d'un excès de protéines $(+25 \%)$ par rapport à un régime de base à $12,5 \%$ de protéines, rééquilibrées en acides aminés (à l'exception du TRP), provoque

Figure 3. Effets d'interaction entre les teneurs en tryptophane et en acides aminés neutres de grande taille dans le régime sur les concentrations de 5hydroxyindoles dans le cerveau et sur l'appétit.

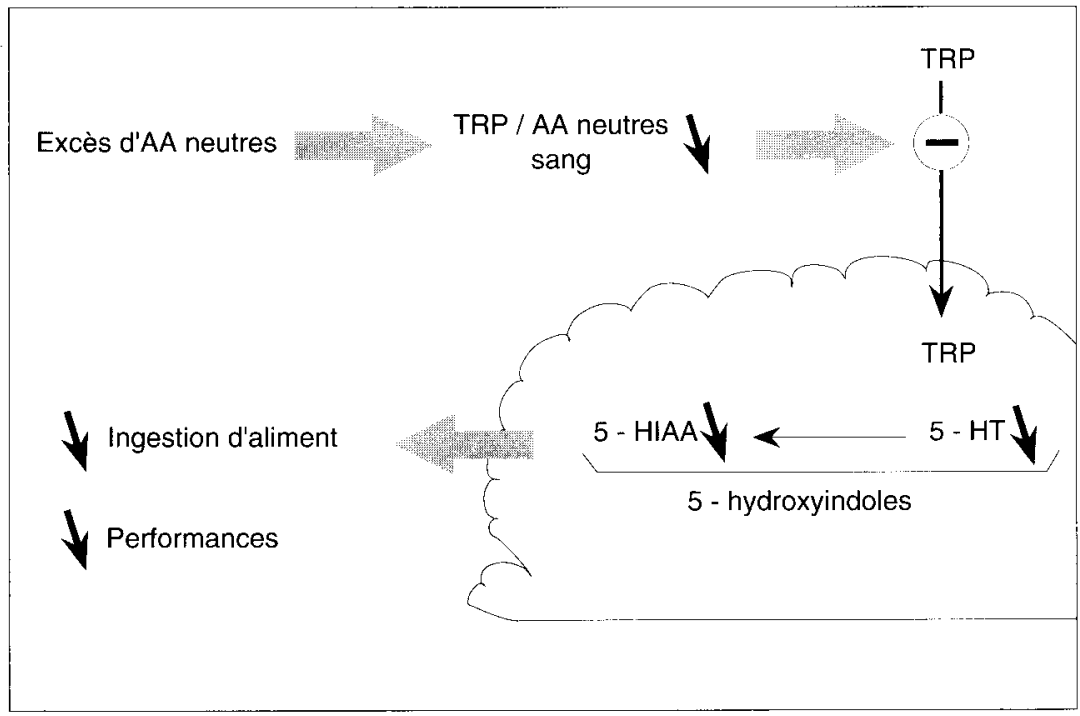

5 - HT : sérotonine (5 - hydroxytryptamine), 5 - HIAA : acide, 5 - hydroxyindole acétique. Le signe "-" traduit l'effet d'antagonisme des AA neutres de grande taille sur le tryptophane lors de son passage à travers la barrière hémato-encéphalique. ainsi un effet dépressif sur la consommation spontanée d'aliment et les performances de croissance (tableau 4). Cet effet dépressif est en relation directe avec l'excès d'AAN par rapport au TRP, que ce soit dans le plasma ou dans l'aliment. Il est surtout accusé lorsque le régime est faiblement pourvu en TRP, et plus important chez les femelles que chez les mâles castrés (tableau 5). Mais, même à un taux de TRP considéré comme optimal, l'addition de protéines entraîne une réduction du niveau d'ingestion alimentaire. Ce déséquilibre entre les acides aminés neutres en excès et le tryptophane, qui se classe parmi les acides aminés les plus limitants, permettrait ainsi d'expliquer l'autolimitation de la consommation d'aliment chez le porc consommant des régimes à teneur élevée en protéines.

Un excès de protéines (ou d'acides aminés neutres) par rapport au tryptophane induit par ailleurs une diminution de la concentration de sérotonine au niveau hypothalamique (figure 4). La plus faible concentration de 5-HT chez les femelles que chez les mâles castrés permettrait d'expliquer leur plus grande sensibilité à un faible ratio TRP / AAN. En d'autres termes, un apport insuffisant de TRP par rapport aux AAN pourrait être à l'origine d'un abaissement de la libération de 5-HT dans les centres régulateurs de l'appétit en dessous d'un seuil préjudiciable au maintien de la consommation d'aliment à son niveau optimum, ce seuil étant plus faible chez les femelles que chez les mâles castrés. Compte tenu d'une plus grande exigence des femelles en acides aminés, comparativement aux mâles castrés, on peut aussi penser à une disponibilité moindre de TRP dans le cerveau pour la synthèse de 5-HT.

Sur un plan pratique, on peut se demander s'il ne convient pas de corriger le rapport TRP / lysine en fonction de l'excès d'AAN relativement au TRP, en vue du maintien d'un niveau optimal de consommation d'aliment et de performances de croissance. Pour une protéine idéale dont le rapport TRP / AAN atteint $5 \%$, le besoin en TRP s'établit à 0,18 de celui de la lysine. Utilisant des régimes purifiés, avec un rapport TRP / AAN supérieur à $5 \%$, Chung et Baker (1992c) ont ainsi montré qu'un rapport

Tableau 4.

Effets d'interaction entre les teneurs en tryptophane et en protéines du régime sur l'ingestion alimentaire et les performances de croissance du porc (Henry et al 1992b)

\begin{tabular}{|c|c|c|c|c|}
\hline Tryptophane (\%) & \multicolumn{2}{|c|}{0,09} & \multicolumn{2}{|c|}{0,13} \\
\hline $\begin{array}{l}\text { Régime } \\
\text { Protéines }(\%)\end{array}$ & $\begin{array}{c}\text { Témoin } \\
12,6\end{array}$ & $\begin{array}{c}\text { Add.Prot. } \\
15,7\end{array}$ & $\begin{array}{r}\text { Témoin } \\
12,6\end{array}$ & $\begin{array}{c}\text { Add.Prot. } \\
15,7\end{array}$ \\
\hline Aliment ingéré $(\mathrm{kg} / \mathrm{j})$ & 2,58 & $\begin{array}{c}1,96 \\
(-24 \%)\end{array}$ & 2,86 & $\begin{array}{c}2,71 \\
(-5 \%)\end{array}$ \\
\hline Gain moyen $(\mathrm{g} / \mathrm{j})$ & 819 & $\begin{array}{c}560 \\
(-32 \%)\end{array}$ & 945 & $\begin{array}{c}899 \\
(-5 \%)\end{array}$ \\
\hline Indice de consommation & 3,15 & $\begin{array}{c}3,74 \\
(+19 \%)\end{array}$ & 3,04 & 3,0 \\
\hline
\end{tabular}

Résultats entre 44 et $99 \mathrm{~kg}$ de poids vif. Add.Prot. : addition de protéines $(+25 \%)$ au régime Témoin. 20 animaux (10 femelles et 10 mâles castrés) par traitement. 


\begin{tabular}{|l|cc|cc|}
\hline Sexe & \multicolumn{2}{|c|}{ Femelles } & \multicolumn{2}{c|}{ Mâles castrés } \\
\hline \multirow{3}{*}{ Protéines $(\%)$} & Témoin & Add.Prot. & Témoin & Add.Prot. \\
& 12,6 & 15,7 & 12,6 & 15,7 \\
Aliment ingéré $(\mathrm{kg} / \mathrm{j})$ & 2,39 & 1,65 & 2,76 & 2,27 \\
& & $(-31 \%)$ & & $(-18 \%)$ \\
Gain moyen $(\mathrm{g} / \mathrm{j})$ & 768 & 449 & 869 & 870 \\
& & $(-42 \%)$ & & $(-23 \%)$ \\
Indice de consommation & 3,12 & 3,97 & 3,18 & 3,51 \\
& & $(+27 \%)$ & & $(+10 \%)$ \\
\hline
\end{tabular}

Résultats entre 44 et $99 \mathrm{~kg}$ de poids vif. Add.Prot. : addition de protéines (+ $25 \%$ ) au régime Témoin. 20 animaux (10 femelles et 10 mâles castrés) par traitement.

Figure 4. Variations des concentrations d'hydroxyindoles (en $n g / g$ de tissu frais) dans l'hypothalamus postérieur du porc en croissance, selon les taux de tryptophane et de protéines, en fonction du type sexuel, selon le taux de tryptophane et le type sexuel.

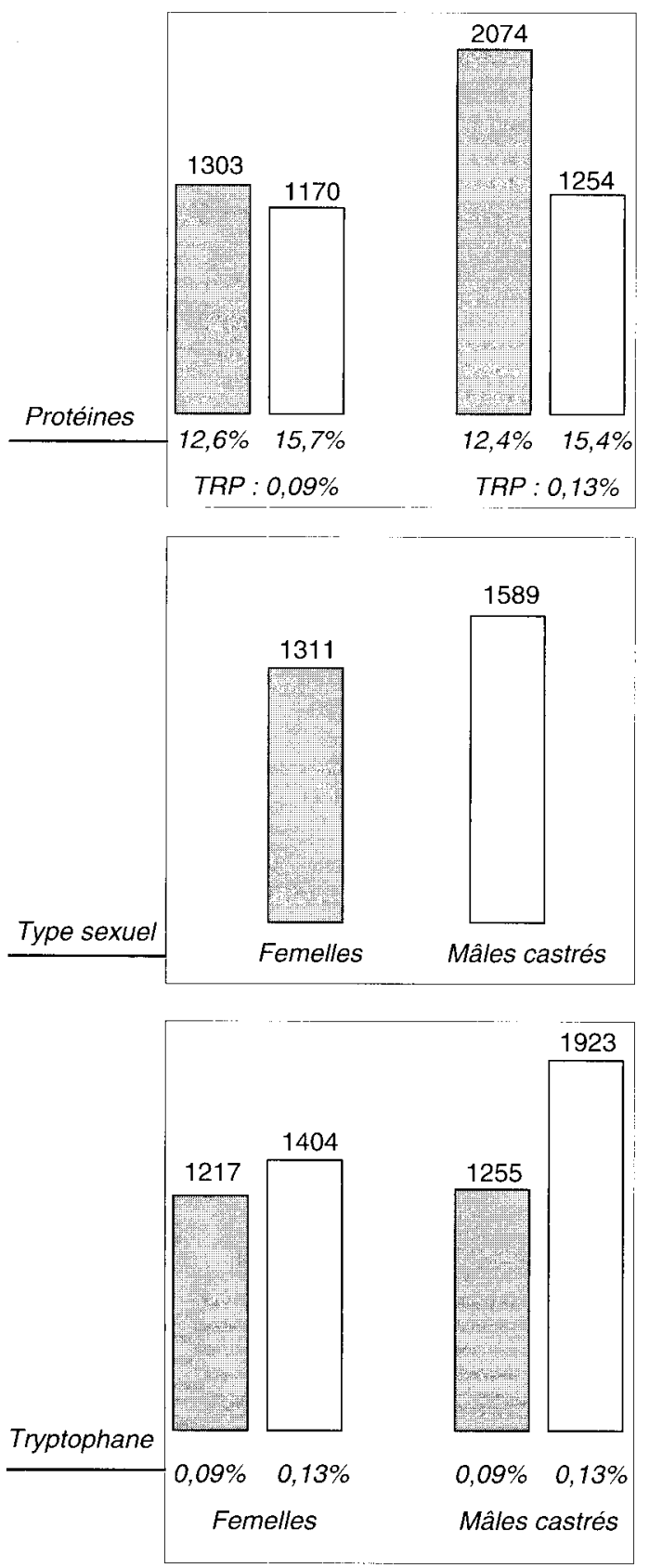

TRP / lysine de 0,18 est nécessaire pour obtenir le niveau optimal de consommation d'aliment et de croissance chez le porcelet entre 10 et $20 \mathrm{~kg}$ de poids vif. Dans les conditions habituelles d'alimentation, le rapport TRP / AAN se situe à un niveau nettement inférieur et peut affecter le niveau du besoin en TRP relativement à celui de la lysine. C'est ce que nous avons voulu vérifier dans une étude réalisée sur des porcs en finition recevant un régime expérimental à teneur élevée en AAN (à base de maìs, pois, gluten de maïs), en alimentation à volonté (Henry et Sève 1993a, tableau 6). Les meilleures performances (consommation d'aliment, vitesse de croissance et indice de consommation) en réponse à un apport supplémentaire de TRP sont obtenues au taux de $0,17 \%$ (rapport TRP / AAN de $4,1 \%$ et TRP / lysine de 0,22$)$, supérieur à celui $(0,14 \%)$ correspondant au rapport TRP / lysine de 0,18 recommandé pour la protéine idéale. Autrement dit, la prise en compte, lors de la formulation des aliments pour le porc, d'un rapport minimum TRP / AAN de $4 \%$, intermédiaire entre un niveau déficient et celui de la protéine idéale, permet de prévenir le risque d'un effet dépressif d'un excès d'acides aminés neutres et / ou de protéines sur l'appétit et la croissance. Cela revient à corriger le rapport TRP / lysine en fonction du profil de composition en AAN du régime (rapport TRP / AAN), ce qui conduit à mettre en défaut la constance du rapport TRP / lysine dans la protéine alimentaire. Chung et Baker (1992c) concluent de la même manière que le rapport TRP / lysine nécessaire pour optimiser la consommation d'aliment chez le jeune porc est plus élevé que celui requis pour la rétention azotée (utilisation métabolique) optimale (en alimentation égalisée).

\section{4 / Thréonine : interaction avec les acides aminés non indispensables}

Les particularités métaboliques de la thréonine chez le porc, notamment au niveau des voies d'oxydation, ont été soulignées antérieurement (Sève et Ballèvre 1991) : en particulier, l'oxydation de la thréonine participe à la formation de glycine, acide aminé non indispensable. Comme pour la lysine et le tryptophane,
Tableau 5.

Effets dinteraction entre la teneur en protéines du régime et le sexe, pour un taux marginal de tryptophane $(0,09 \%)$ (Henry et al 1992b)

\section{Un excès d'acides aminés neutres par rapport au tryptophane entraîne une réduction de l'ingestion alimentaire, même si le taux de tryptophane est optimal.}


Tableau 6.

Influence de la teneur en tryptophane (TRP) et du rapport tryptophane / acides aminés neutres (TRP / AAN) dans le régime sur l'ingestion alimentaire et les performances du porc en finition (Henry et Sève 1993a)

\begin{tabular}{|c|c|c|c|c|c|c|}
\hline Type de régime $^{b}$ & Témoin & \multicolumn{4}{|c|}{ Expérimental } & \\
\hline TRP total $(\%)^{\mathrm{C}}$ & 0,19 & 0,12 & 0,14 & 0,17 & 0,20 & \\
\hline TRP / lysine $e^{d}$ & 0,24 & 0,15 & 0,18 & 0,22 & 0,27 & \\
\hline TRP/AAN, $\%^{d}$ & 5,1 & 2,7 & 3,3 & 4,1 & 4,9 & \\
\hline Protéines, $\%$ & 15,5 & 15,3 & 15,5 & 15,4 & 15,2 & \\
\hline & & & & & & $\mathrm{S}_{\overline{\mathrm{x}}}^{\mathrm{e}}$ \\
\hline Aliment ingéré $(\mathrm{kg} / \mathrm{j})$ & 2,83 & 2,11 & 2,55 & 2,66 & 2,74 & 0,05 \\
\hline Gain moyen $(\mathrm{g} / \mathrm{j})$ & 1004 & 635 & 858 & 921 & 956 & 18 \\
\hline Gain de muscle $(\mathrm{g} / \mathrm{j})$ & 424 & 290 & 376 & 406 & 416 & 9 \\
\hline Dépôt gras $(\mathrm{g} / \mathrm{j})$ & 200 & 111 & 169 & 179 & 200 & 9 \\
\hline Indice de consommation & 2,81 & 3,36 & 2,98 & 2,89 & 2,87 & 0,04 \\
\hline
\end{tabular}

${ }^{a}$ Résultats entre 40 et $100 \mathrm{~kg}$ de poids vif. 20 animaux croisés Piétrain x Large White (10 femelles et 10 mâles castrés) par traitement. Alimentation à volonté.

${ }^{b}$ Régime témoin blé - tourteau de soja. Régime expérimental à base de maiss, t.soja, pois, gluten feed et gluten de maïs.

Teneurs en acides aminés totaux (digestibles entre parenthèses), \%: lysine : témoin, $0,80(0,70)$; expérimental : $0,77(0,67)$.

Thréonine : $0,56(0,45)$. Méthionine : $0,26(0,22)$. Méthionine + cystine : 0,51 .

${ }^{c}$ Les teneurs en TRP digestible vrai étaient respectivement $0,17-0,10-0,12-0,15$ et 0,18 .

${ }^{d}$ Rapports exprimés en digestibilité iléale vraie. AAN (acides aminés neutres de grand taille) : leucine + isoleucine + valine + phénylalanine + tyrosine.

"Ecart-type de la moyenne.

nous avons voulu vérifier l'existence d'une interaction éventuelle entre les protéines additionnelles, selon leur nature (acides aminés indispensables et non indispensables), et un apport limitant de thréonine, du point de vue des effets sur l'ingestion alimentaire et les performances de croissance. Les résultats obtenus (Le Floc'h et al 1993, tableau 7) montrent qu'à un taux suboptimum de thréonine pour la croissance, l'addition d'acides aminés non indispensables sous forme d'acide glutamique entraîne une amélioration du gain pondéral et du gain de muscle, accompagnée d'une meilleure efficacité alimentaire. Ceci semble faire apparaitre un effet d'épargne de l'acide glutamique sur la thréonine, lorsque celle-ci est limitante pour la croissance. Des observations complémentaires sont néanmoins nécessaires pour approfondir cette synergie. Cela montre en tout cas qu'il n'y a pas de frontière nette entre les acides aminés indispensables et non indispensables.

S'agissant du rapport thréonine / lysine, sa valeur optimale pour la croissance, sur la base de la digestibilité iléale, semble se situer aux alentours de 0,65 , de préférence à 0,60 , comme le suggéraient les recommandations initiales (ARC 1981, INRA 1984). C'est ce qui ressort de nos observations (Henry et Bourdon 1993, figure 5), relatives aux variations du gain pondéral pendant la phase initiale de l'engraisse-

Tableau 7. Interaction entre la teneur en thréonine et l'addition d'acide glutamique dans le régime sur les performances du porc en finition (Le Floc'h et al 1993)

\begin{tabular}{|l|ccc|ccc|c|}
\hline Thréonine $(\%)$ & \multicolumn{3}{|c|}{0,42} & \multicolumn{3}{c|}{0,52} & \\
\hline & $\mathrm{T}^{\mathrm{b}}$ & $+\operatorname{Prot}^{\mathrm{c}}$ & + AANI $^{\mathrm{d}}$ & $\mathrm{T}^{\mathrm{b}}$ & + Prot $^{\mathrm{c}}$ & +AANI $^{\mathrm{d}}$ & \\
Prot.brutes $(\%)^{\mathrm{h}}$ & 12,9 & 15,6 & 14,8 & 13,0 & 15,5 & 14,5 & $\mathrm{~S}_{\overline{\mathrm{x}}}^{\mathrm{e}}$ \\
& & & & & & & \\
Aliment ingéré $(\mathrm{kg} / \mathrm{j})$ & 2,56 & 2,54 & 2,68 & 2,83 & 2,81 & 2,74 & 0,04 \\
Gain moyen $(\mathrm{g} / \mathrm{j})$ & 849 & 818 & 908 & 1055 & 1039 & 1037 & 22 \\
Gain de muscle $(\mathrm{g} / \mathrm{j})$ & 345 & 344 & 371 & 424 & 425 & 420 & 9 \\
Dépôt gras $(\mathrm{g} / \mathrm{j})$ & 173 & 147 & 175 & 206 & 203 & 211 & 8 \\
Indice de consommation & 3,06 & 3,14 & 2,97 & 2,68 & 2,70 & 2,64 & 0,04 \\
\hline
\end{tabular}

${ }^{a}$ Résultats entre 40 et 102 kg de poids vif. Porcs croisés Piétrain x Large White : 20 animaux (10 femelles et 10 mâles castrés) par traitement. Alimentation à volonté.

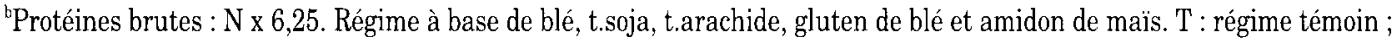
+Prot : addition de protéines ; +AANI : addition d'acides aminés non indispensables.

'Addition de protéines, en maintenant les mêmes proportions entre les composants du régime de base, à l'exception de l'amidon de maïs.

${ }^{d}$ Addition d'acide L-glutamique $(2,5 \%)$ et de glutamate monosodique (1,0\%) pour apporter la même quantité d'N non indispensable qu'avec l'addition de protéines.

${ }^{e}$ Ecart-type de la moyenne. 
ment (entre 28 et $50 \mathrm{~kg}$ de poids vif), en fonction de la teneur en thréonine digestible vraie, dans les conditions d'alimentation rationnée selon un mode libéral et dans un régime de type blé - tourteau de soja à taux réduit de protéines, pour une teneur en lysine ajustée au besoin pour une croissance optimale. Celle-ci étant atteinte aux taux respectifs de thréonine et de lysine digestibles de 0,48 et $0,74 \%$, le rapport thréonine / lysine correspondant s'élevait à $0,48 / 0,74=0,65$, en valeur de digestibilité iléale vraie. Ce résultat est en accord avec les observations faites récemment par Wang et Fuller (1990), Sève et al (1993), ainsi que par les chercheurs néerlandais (Lenis et al 1990 , Lenis et van Diepen 1990, Schutte et al 1990 , Lenis 1992).

\section{5 / Méthionine : en équilibre avec la cystine}

Il est admis, à partir d'un grand nombre de travaux expérimentaux (ARC 1981, INRA 1984, NRC 1988, Roth et Kirchgessner 1987, 1989, Kiener et Kies 1990, Schutte et al 1991, Chung et Baker 1992a,b) que la méthionine doit participer pour au moins 50 à $55 \%$ à la couverture du besoin total en acides aminés soufrés (méthionine + cystine) chez le porc en croissance. Or, dans la plupart des aliments consommés par le porc, le pourcentage de méthionine dans les acides aminés soufrés totaux est inférieur à $50 \%$; il s'abaisse même à $40 \%$ seulement dans les céréales à paille (blé orge), les issues de céréales et le pois fourrager. Ainsi, dans les conditions habituelles d'alimentation, la cystine est majoritaire dans les acides aminés soufrés. Dès lors, la formulation des aliments pour le porc sur la base des acides aminés soufrés totaux ne suffit pas. Il convient prioritairement de prendre en compte le besoin spécifique en méthionine relativement au besoin en lysine, pour assurer l'équilibre optimal au sein des acides aminés soufrés et par rapport aux autres acides aminés indispensables (rapport méthionine / lysine). Par ailleurs, le rapport méthionine / acides aminés soufrés n'a pas la même valeur suivant que les teneurs en acides aminés sont exprimées en quantités brutes (ce qui a été le cas pour la plupart des études réalisées jusqu'à présent) ou en quantités digestibles. Dans ce dernier cas, en raison de la plus faible digestibilité de la cystine relativement à la méthionine, le rapport méthionine / acides aminés soufrés est accru.

Suivant les sources bibliographiques, les apports recommandés de méthionine + cystine relativement à la lysine pour le porc en croissance varient de 0,50 (ARC 1981) à 0,60 (INRA 1984, Wang et Fuller 1990, Chung et Baker 1991). Sur la base d'une proportion minimale de 0,50 à 0,55 de méthionine dans les acides aminés soufrés, on en déduit que le rapport méthionine / lysine recommandé oscille entre

Figure 5. Influence de la teneur en thréonine digestible du régime sur la vitesse de croissance pendant la première phase de l'engraissement du porc : réponse à une addition de méthionine selon le taux de thréonine (Henry et Bourdon 1993). Régimes à base de blé et de tourteau de soja ; alimentation selon un plan de rationnement. Les teneurs en acides aminés sont exprimées en digestibilité iléale vraie ( $d v$ ).

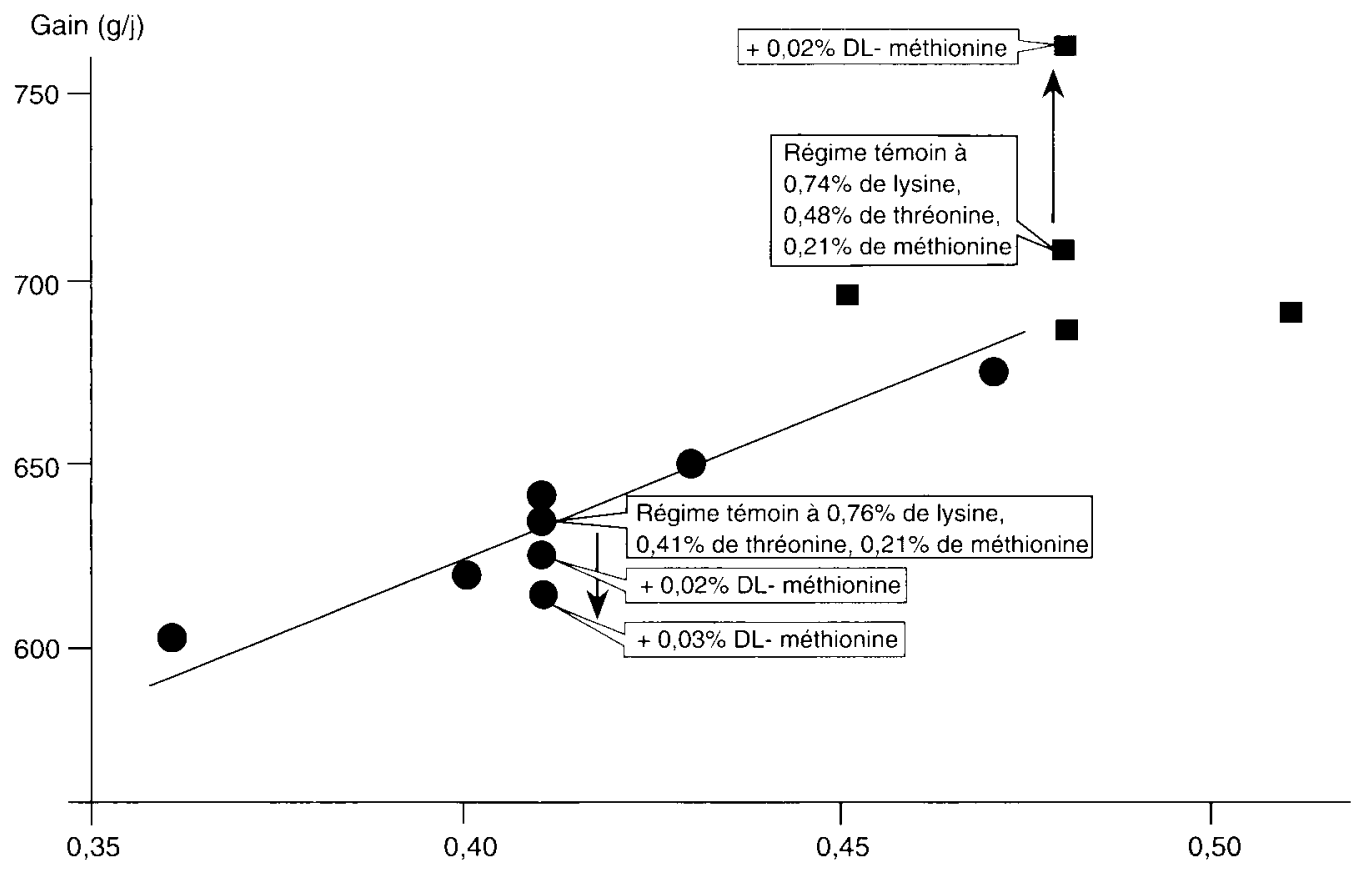

Teneur en thréonine $(\mathrm{dv}, \%)$

\section{L'apport supplémentaire de méthionine, dans un régime à base de blé normalement pourvu en lysine, est favorable après complémentation en lysine et en thréonine, seulement lorsque le taux de thréonine est optimal, sinon l'effet est négatif.}


0,25 et 0,30 . A la suite d'observations antérieures (Henry et al 1988, Henry et al 1992a), les résultats du tableau 8 (Henry et Bourdon 1993) semblent en faveur d'un rapport méthionine / lysine d'au moins 0,30 en vue de l'obtention de performances optimales de croissance et d'efficacité alimentaire, et sont en accord avec ceux de Lenis et al (1990) et Lenis (1992). Dans un régime de type blé-tourteau de soja à $15,5 \%$ de protéines chez le porc en finition (figure 5), une supplémentation combinée en méthionine après la lysine et la thréonine (respectivement les acides aminés limitants primaire et secondaire), et pour un taux optimal de thréonine $(0,48 \%$ digestible), procure ainsi une amélioration supplémentaire de la croissance en début d'engraissement. A l'opposé, un

\begin{tabular}{|c|c|c|c|c|}
\hline \multirow{5}{*}{$\begin{array}{r}\text { Tableau } 8 . \\
\text { Influence du rapport } \\
\text { méthionine / lysine sur les } \\
\text { performances de } \\
\text { croissance du porc entre } \\
28 \text { et } 60 \mathrm{~kg} \text { de poids vif } \\
\text { (Henry et Bourdon 1993) }^{a}\end{array}$} & $\begin{array}{l}\text { DL-méthionine supp. }(\%) \\
\text { Méthionine dig. }(\%)^{\mathrm{b}} \\
\text { Lysine dig. }(\%)^{\mathrm{b}} \\
\text { Rapport méthionine/lysine }\end{array}$ & $\begin{array}{c}- \\
0,21 \\
0,74 \\
0,28\end{array}$ & $\begin{array}{l}0,02 \\
0,23 \\
0,74 \\
0,31\end{array}$ & \\
\hline & \multicolumn{4}{|r|}{$\mathrm{s}_{\mathrm{X}}^{\mathrm{c}}$} \\
\hline & Aliment ingéré $(\mathrm{kg} / \mathrm{j})$ & 1,97 & 2,04 & \\
\hline & Gain moyen $(\mathrm{g} / \mathrm{j})$ & 714 & 766 & 16 \\
\hline & Indice de consommation & 2,77 & 2,62 & 0,07 \\
\hline
\end{tabular}

"Régime blé - tourteau de soja à 15,5\% MAT. 12 animaux ( 6 femelles et 6 mâles castrés) par traitement.

Alimentation rationnée de type libéral.

"Les teneurs en acides aminés sont exprimées en digestibilité iléale vraie.

'Ecart-type de la moyenne. apport supplémentaire de méthionine, toujours après la lysine et la thréonine, mais pour un taux suboptimal de cette dernière $(0,41 \%$ digestible), provoque un effet dépressif sur la croissance, d'autant plus important que la dose supplémentaire de méthionine est plus élevée (respectivement 0,02 et $0,05 \%$ ). Il s'agit là d'un cas typique de déséquilibre (ou "imbalance") entre un acide aminé apporté en excès (méthionine) par rapport à un autre acide aminé apporté en quantité insuffisante (thréonine) dans un régime où la hiérarchie habituelle des acides aminés limitants n'est plus respectée.

Il a été fait état précédemment d'un déséquilibre au sein du groupe des acides aminés neutres de grande taille, par référence au tryptophane. La méthionine est également un acide aminé neutre, et on ne saurait exclure a priori un risque de déséquilibre entre la méthionine par défaut et les AAN par excès. Dans la protéine idéale, le ratio méthionine / AAN se situe aux alentours de $8 \%$. Nous avons voulu vérifier l'intérêt éventuel d'une élévation de ce rapport au delà d'une valeur de $6,0 \%$ mesurée dans un régime expérimental à teneur élevée en AAN (Henry et Sève 1993a). Les résultats du tableau 9 ne font apparaitre aucun effet sur la consommation spontanée d'aliment ni sur les performances de croissance. On peut en déduire une absence d'interaction entre la méthionine et les acides aminés neutres de grande taille, tout au moins dans les conditions d'un excès modéré pour ces derniers.

Tableau 9. Influence du rapport méthionine / acides aminés neutres (MET / AAN) sur l'ingestion alimentaire et les performances de croissance du porc en finition (Henry et Sève 1993).

\begin{tabular}{|c|c|c|c|c|}
\hline Type de régime" & Témoin & \multicolumn{2}{|c|}{ Expérimental } & \\
\hline Méthionine dig. (\%) (3) & 0,22 & 0,22 & 0,27 & \\
\hline MET / lysine & 0,31 & 0,31 & 0,38 & \\
\hline MET / AAN $(\%)$ & 6,7 & 6,0 & 7,4 & \\
\hline Protéines (\%) & 15,5 & 15,2 & 15,4 & \\
\hline Aliment ingéré $(\mathrm{kg} / \mathrm{j})$ & 283 & 274 & 274 & $\begin{array}{c}S_{\mathrm{x}}{ }^{\mathrm{e}} \\
0.05\end{array}$ \\
\hline $\begin{array}{l}\text { Aliment ingéré }(\mathrm{kg} / \mathrm{j}) \\
\text { Gain moyen }(\mathrm{g} / \mathrm{j})\end{array}$ & 1004 & 956 & 964 & 18 \\
\hline Gain de muscle $(g / j)$ & 424 & 416 & 421 & 9 \\
\hline Dépôt gras $(\mathrm{g} / \mathrm{j})$ & 200 & 200 & 193 & 9 \\
\hline Indice de consommation & 2,81 & 2,87 & 2,84 & 0,04 \\
\hline
\end{tabular}

"Résultats entre 40 et $101 \mathrm{~kg}$ de poids vif. 20 porcs croisés Piétrain x Large White (10 femelles et 10 mâles castrés) par traitement. Alimentation à volonté.

"Régime témoin blé - tourteau de soja. Régime expérimental à base de mais, t.soja, pois, gluten feed de mais et gluten de maïs.

Teneurs en acides aminés totaux (digestibles entre parenthèses). Lysine : témoin : $0,80(0,70)$; expérimental : $0,77(0,70)$.

Thréonine : $0,56(0,45)$. Tryptophane : témoin : $0,19(0,17)$; expérimental : $0,20(0,18)$.

"Teneurs en méthionine totale, respectivement $0,25-0,26$ et 0,31 ; en méthionine + cystine, respectivement $0,51-0,51$ et $0,56 \%$.

${ }^{d}$ Acides aminés neutres de grand taille (AAN) : leucine + isoleucine + valine + phénylalanine + tyrosine.

"Ecart-type de la moyenne. 


\section{Conclusion}

Le concept de la protéine idéale dans l'alimentation du porc présente l'avantage de permettre une vision intégrée des besoins en acides aminés indispensables en relation avec un apport complémentaire minimum d'acides aminés non indispensables. Les ratios acides aminés / lysine qui s'en dégagent (de préférence sur la base de la digestibilité iléale) constituent une base à la fois commode et suffisamment rigoureuse pour la formulation des aliments pour les porcs. Cela étant, on ne saurait envisager une réduction simplificatrice de la protéine alimentaire, naturellement déséquilibrée (à des degrés d'ailleurs divers selon l'origine des ingrédients), à une composante "protéine idéale" qui déterminerait à elle seule le niveau et la qualité de la production. Nous avons vu que les écarts entre la protéine alimentaire et sa fraction "idéale" ou équilibrée ne sont pas neutres et peuvent agir d'une manière spécifique sur l'appétit, l'utilisation métabolique et les performances de production. C'est la raison pour laquelle, compte tenu de la spécificité des fonctions de chaque acide aminé, il convient d'adapter les apports acides aminés / lysine, non seulement en fonction des besoins des animaux, mais aussi en fonction du profil de composition en acides aminés de l'aliment qu'ils consomment. Ceci amène dans certains cas à corriger le besoin pour un acide aminé particulier relativement à la lysine, dont le choix comme acide aminé de référence se justifie par sa contribution active à la formation des dépôts corporels, et à l'inverse par son rôle peu actif dans les processus métaboliques. L'exemple le plus typique est donné par le tryptophane, qui interagit négativement avec les acides aminés neutres de grande taille, plus abondants dans certaines associations alimentaires, et plus généralement dans les régimes riches en protéines. Pour se prémunir contre ce risque de déséquilibre, préjudiciable à l'appétit et à la croissance, il y a lieu de s'assurer, lors de la formulation des aliments, que le rapport tryptophane / acides aminés neutres est d'au moins $4 \%$, de manière à corriger en conséquence le rapport tryptophane / lysine. Afin de synthétiser les informations recueillies, nous avons regroupé dans le tableau 10, pour les différents acides aminés indispensables, les relations d'équilibre considérées comme optimales par rapport à la lysine.

Si la protéine idéale n'existe pas dans la pratique, elle n'en constitue pas moins un objectif réaliste quant à l'amélioration de l'équilibre en acides aminés, associée à à une réduction quantitative des intrants azotés alimentaires. Nous avons eu l'occasion (Henry 1988, Henry et Sève 1993b) de souligner l'impact bénéfique d'un rééquilibrage des acides aminés du régime sur l'ingestion alimentaire et les performances de croissance, d'une façon probablement priviligiée chez les porcs à haut niveau de croissance musculaire et connus pour leur appétit limité. L'effet également favorable sur l'utilisation de l'énergie, en raison d'un coût moindre pour la dégradation des acides aminés en excès, conduit à une meilleure valorisation énergétique des aliments à teneur modérée en protéines et mieux pourvus en amidon. Cette valorisation de l'énergie alimentaire, par rapport à des situations de plé-

Tableau 10. Rapports acides aminés / lysine recommandés pour la croissance du porc : synthèse des résultats

\begin{tabular}{|lc|c|c|c|}
\hline & $\begin{array}{c}\text { Chung et Baker } \\
(1991,1992 \mathrm{c})^{\mathrm{b}}\end{array}$ & $\begin{array}{c}\text { Wang et Fuller } \\
(1990)^{\mathrm{r}}\end{array}$ & $\begin{array}{c}\text { Lenis } \\
(1992)^{\mathrm{k}}\end{array}$ & $\begin{array}{c}\text { Nos résultats et } \\
\text { recommandations }\end{array}$ \\
\hline Acides aminés & 1,00 & 1,00 & 1,00 & \\
Lysine & $0,30^{\mathrm{b}}$ & & $0,32^{\mathrm{d}}$ & 1,00 \\
Méthionine & 0,60 & 0,61 & 0,59 & 0,30 \\
Méthionine+ cystine & 0,65 & 0,64 & 0,63 & 0,60 \\
Thréonine & 0,18 & 0,20 & 0,19 & 0,65 \\
Tryptophane & 0,60 & & & 0,60 \\
Isoleucine & 1,00 & & & 1,00 \\
Leucine & 0,68 & & & 0,70 \\
Valine & 0,32 & & & 0,32 \\
Histidine & 0,95 & & & 1,00 \\
Phénylalanine+ tyrosine & 0,42 & & & 0,45 \\
Arginine & & & \\
\hline
\end{tabular}

*Correction : $\min .4 \%$ TRP/AAN.

"Rapports exprimés en terme de digestibilité iléale des acides aminés.

"Jeune porc entre 10 et $20 \mathrm{~kg}$ de poids vif. Régime purifié à base d'acides aminés sous forme libre : digestibilité proche de $100 \%$ (Chung et Baker, 1992d) ; 14,8\% de protéines ( $\mathrm{N}$ x 6,25) et $3450 \mathrm{Kcal} \mathrm{EM} / \mathrm{kg} ; 50 \%$ de méthionine (base pondérale) dans les acides aminés soufrés ; rapport $\mathrm{N}$ indispensable / $\mathrm{N}$ non indispensable $: 0,96$.

'Porc en croissance : $30 \mathrm{~kg}$ de poids vif.

${ }^{`}$ Porc en croissance - finition ( $45-105 \mathrm{~kg}$ de poids vif). La méthionine contribue pour $54 \%$ des acides aminés soufrés digestibles.

'Porc en croissance - finition (25 - $100 \mathrm{~kg}$ de poids vif). Légère augmentation prévisible des ratios méthionine, thréonine et tryptophane, relativement à la lysine, en fonction de l'âge ou du poids vif. 
thore de protéines et génératrices d'excédents d'azote, est la meilleure au travers du système d'énergie nette (Noblet et al 1989, Noblet et Henry 1991). L'objectif "protéine idéale" (ou équilibrée) permet de ce fait d'entrevoir les possibilités de réduction des rejets azotés dans les effluents (lisier) et l'atmosphère (ammoniac) grâce à une gestion raisonnée des intrants azotés alimentaires (Henry 1991, Dourmad et al 1992, Henry et Dourmad 1992). Il est vraisemblable que plus on se rapprochera de la protéine idéale, ce qui parâ̂t encore utopique, moins les problèmes de déséquilibre en acides aminés se poseront dans la pratique, à l'image du modèle "maïs - soja" américain.

En définitive, la mise à l'épreuve de la protéine idéale dans les conditions habituelles de l'alimentation du porc a permis de mettre en évidence l'importance des problèmes de déséquilibre entre les acides aminés, en relation avec la spécificité de leurs fonctions métabo- liques et physiologiques et de leurs affinités. Il s'en est ainsi dégagé le rôle particulier des acides aminés neutres vis-à-vis du tryptophane. Le cas de la thréonine a montré qu'il n'existe pas de frontière étanche entre les acides aminés indispensables d'un côté et les acides aminés non indispensables de l'autre, ce qui milite en faveur d'un renforcement des travaux visant à une meilleure connaissance des voies métaboliques pour certains d'entre eux. L'approche critique de la protéine idéale, par l'approfondissement des mécanismes qui soustendent les déséquilibres entre les acides aminés, constitue une bonne garantie pour un affinement encore plus complet vers une protéine parfaitement équilibrée dans les applications à venir.

Rapport présenté à la Session CAAA - AFTAA "Monogastriques. Nutrition énergétique et azotée", 5-6 Novembre 1992, Tours.

\section{Références bibliographiques}

ARC, 1981. The Nutrient Requirements of Pigs. C.A.B., Farnham Royal, Slough, England, 307 pp.

Batterham, E.S., Andersen L.M., Baigent D.R., White E., 1990. Utilisation of ileal digestible amino acids by growing pigs : effect of dietary lysine concentration on efficiency of lysine retention. Brit.J.Nutr., 64, 81-94.

Christensen H.N., 1975. Biological Transport. W.A.Benjamin, Inc., Reading, Massachusets, 178 pp.

Chung T.K., Baker D.H., 1991. A chemically defined diet for maximal growth of pigs. J. Nutr., 121, 979. 984

Chung T.K., Baker D.H., 1992a. Maximal portion of the young pig's sulfur amino acid requirement that can be furnished by cystine. J.Anim.Sci., 70, 11821187.

Chung T.K., Baker D.H., 1992b. Methionine requirement of pigs between 5 and 20 kilograms body weight. J.Anim.Sci., 70, 1857-1863.

Chung T.K., Baker D.H. 1992c. Ideal amino acid pattern for 10-kilogram pigs. J.Anim.Sci., 70, 31023111 .

Chung T.K., Baker D.H., 1992d. Apparent and true amino acid digestibility of a cristalline amino acid mixture and of casein : comparison of values obtained with ileal-cannulated pigs and cecectomized cockerels. J.Anim.Sci., 70, 3781-3790.

Cole D.J.A., 1979. Amino acid nutrition of the pig. In : W.Haresign and D.Lewis (Ed.) Recent Advances in Animal Nutrition-1978 . Butterworths, London, pp 59-72.

Cole D.J.A., 1980. The amino acid requirements of pigs - the concept of an ideal protein. Pig News and Information, 1 (3), 201-205.

Dourmad J.Y., Etienne M., Noblet J., 1991. Contribution à l'étude des besoins en acides aminés de la truie en lactation. Journées Rech. Porcine en France, 23, 61-68.
Dourmad, J.Y., Guillou D., Noblet J., 1992. Development of a calculation model for predicting the amount of $\mathrm{N}$ excreted by the pig: effect of feeding, physiological stage and performance. Livest.Prod.Sci., 31, 95-107.

Fisher C., 1983. The physiological basis of the amino acid requirements of poultry. In : M.Arnal, R.Pion and D.Bonin (Ed.) Protein Nutrition and Metabolism. Les Colloques de l'INRA (EAAP Pub.N³1), INRA, Paris, Vol.1, pp 385-404.

Fuller, M.F. 1991. Present knowledge of amino acid requirements for maintenance and production: nonruminants. In: B.O. Eggum, S. Boisen, C. Börsting, A. Danfaer and T. Hvelplund (Ed.) Protein Metabolism and Nutrition. Nat. Inst. Anim. Sci., Foulum, DK. EAAP Publ. No 59, Vol. 1, Main reports, pp 116-126.

Fuller, M.F., Mc William R., Wang T.C., Giles L.R., 1989. The optimum dietary amino acid pattern for growing pigs 2. Requirements for maintenance and for tissue protein accretion. Brit. J. Nutr. 62, 255-267.

Henry, Y., 1988. Signification de la protéine équilibrée pour le porc: intérêt et limites. INRA Prod. Anim. 1, 65-74.

Henry Y., 1991. Répercussions des techniques actuelles de production animale sur l'environ-nement. Bull.Acad.Vét.de France (supp.n ${ }^{\circ}$ ), 119-139.

Henry Y., Bourdon D., 1993. Réduction des intrants azotés dans l'alimentation du porc en croissance : utilisation d'un modèle de régime à base de blé avec supplémentation en lysine, thréonine et méthionine. Journées Rech.Porcine en France, 25, 263-272.

Henry Y., Dourmad J.Y., 1992. Protein nutrition and $\mathrm{N}$ pollution in pigs. In : G. Piva Ed, Proc.2nd Internat.Feed Production Conference, Piacenza, Facolta di Agraria (Italia), pp 191-208.

Henry, Y., Sève B., 1991. Incidence de l'équilibre en acides aminés du régime sur l'appétit et la croissance du porc, selon le taux de protéines et leur nature: l'exemple du tryptophane. Journées Rech. Porcine en France, 23, 119-126. 
Henry Y., Sève B., 1993a. Prise en compte de l'excès alimentaire d'acides aminés neutres pour la correction de l'équilibre du tryptophane par rapport à la lysine chez le porc en croissance. Journées Rech.Porcine en France, 25, 247-253.

Henry Y., Sève B., 1993b. Feed intake and dietary amino acid balance in growing pigs with special reference to lysine, tryptophan and threonine. Pig News and Information, $13(1), 35 \mathrm{~N}-43 \mathrm{~N}$.

Henry, Y., Arnal M., Obled C., Rérat A., 1988. Protein and amino acid requirements of pigs ( Proc. Symp. Protein Metabolism and Nutrition, Rostock, O Germany. EAAP Publ. No 35 ). Wiss. Z. Rostock Univ. 37 (1), 9-18.

Henry, Y., Colléaux Y., Sève B., 1992a. Effects of dietary level of lysine and of level and source of protein on feed intake, growth performance and plasma amino acid pattern in the finishing pig. J. Anim. Sci., 70, 188-195.

Henry, Y. Sève B., Colléaux Y., Ganier P., Saligaut C., Jégo P., 1992b. Interactive effects of dietary levels of tryptophan and protein on voluntary feed intake and growth performance in pigs, in relation to plasma free amino acids and hypothalamic serotonin. J. Anim. Sci., 70, 1873-1887.

INRA, 1984. L'alimentation des monogastriques: porc, lapin, volailles. INRA, Paris, $282 \mathrm{pp}$.

Kiener T., Kies A., 1990. Réévaluation du besoin en acides aminés soufrés du porc charcutier. Journées Rech.Porcine en France, 22, 185-192.

Le Floc'h N., Sève B., Henry Y., 1993. Threonine dehydrogenase in growing pig fed threonine deficient diets. Proc.Nutr.Soc., 52 (In press).

Lenis N.P., 1992. Digestible amino acids for pigs : assessment of requirements on ileal digestible basis. Pig News and Information, $13(1), 31$ N-39N.

Lenis N.P., van Diepen J.Th.M., 1990. Amino acid requirements of pigs. 3 . Requirement for apparent digestible threonine of pigs in different stages of growth. Netherlands J.Agric.Sci., 38, 609-622.

Lenis N.P., van Diepen J.Th.M., Goedhart P.W., 1990. Amino acid requirements of pigs. 1 . Requirements for methionine + cystine, threonine and tryptophan of fast-growing boars and gilts, fed ad libitum. Netherlands J.Agric.Sci., 38, 577-595.

Mitchell H.H., 1964. Comparative Nutrition of Man and Domestic Animals. Vol. II. Academic Press, New York, $840 \mathrm{pp}$.

Noblet J., Henry Y., 1991. Energy evaluation systems for pig diets. In : E.S.Batterham (Ed.) Manipulating Pig Production III, Australasian Pig Science Association, Attwood, Victoria (Australia), pp 97-110.

Noblet, J., Henry Y., Dubois S., 1987. Effect of protein and lysine levels in the diet on body gain composition and energy utilization in growing pigs. J. Anim. Sci., 65, 717-726.
Noblet, J., Fortune H., Dubois S., Henry Y., 1989. Nouvelles bases d'estimation des teneurs en énergie digestible, métabolisable et nette des aliments pour le porc. INRA, Paris, 106 pp.

Noblet J., Fortune H., Dupire C., Dubois S., 1990. Valeur nutritionnelle de treize matières premières pour le porc en croissance. 1. Teneurs en énergie digestible, métabolisable et nette; Conséquences du choix du système énergétique. Journées Rech.Porcine en France, 22, 175-183.

NRC, 1988. Nutrient Requirements of Swine. Ninth revised edition. Nutrient Requirements of Domestic Animals. National Academy Press, Washington, D.C., 93 pp.

Roth F.X., Kirchgessner M., 1987. Biological efficiency of dietary methionine or cystine supplementation with growing pigs - A contribution to the requirement for S-containing amino acids. Z.Tierphysiol., Tierernährg.u.Futtermittelkde, 58, 267-280.

Roth F.X., Kirchgessner M., 1989. Influence of the methionine : cysteine relationship in the feed on the performance of growing pigs. Z. Tierphysiol., Tierernährg.u.Futtermittelkde, 61, 265-274.

Schutte J.B., Bosch M.W., Lenis N.P., de Jong J., van Diepen J.T.M., 1990. Amino acid requirements of pigs. 2. Requirements for apparent digestible threonine of young pigs. Netherlands J.Agric.Sci., $38,597-607$.

Schutte J.B., Bosch M.W., de Jong J., van Weerden E.J., Koch F., 1991. Factors affecting the requirement of dietary sulphur-containing amino acids of young pigs. Netherlands J.Agric.Sci., 39, 91101.

Sève B., 1988. La protéine idéale chez les porcins : signification et intérêt. In : AFZ-ITCF (Ed.) Les acides aminés pour porcs : évolutions récentes. SIMAVIP, Paris, pp 7-21.

Sève, B., Ballèvre O., 1991. Approches métaboliques $\mathrm{du}$ besoin en acides aminés chez le porc en croissance. Journées Rech. Porcine en France 23, 91110 .

Sève B., Ganier P., Henry Y., 1993. Courbe de réponse des performances de croissance à l'apport de thréonine digestible vrai mesuré au niveau iléal chez le porc. Journées Rech. Porcine en France, 25, 255261.

Uttecht D.J., Hamilton C.R., Weaver E.W., Libal G.W., 1991. Interaction between dietary levels of neutral amino acids and tryptophan fed to $10-\mathrm{kg}$ pigs. J.Anim.Sci., 69 (Suppt), 364 (Abstr.).

Wang, T.C., Fuller M.F., 1989. The optimum dietary amino acid pattern for growing pigs 1 . Experiments by amino acid deletion. Brit. J. Nutr., 62, 77-89.

Wang T.C., Fuller M.F., 1990. The effect of the plane of nutrition on the optimum dietary amino acid pattern for pigs. Anim.Prod., 50, 155-164. 


\section{Summary}

Refinement of the concept of ideal protein for the growing pig.

The present review was intended to provide recent information on the relationships between dietary amino acids in growing pigs, through the concept of "ideal" protein. The limits of this concept were given, namely with regards to the constant ratios between essential amino acids and lysine, as a reference. The ratios between secondary limiting amino acids (tryptophan, threonine, methionine and sulphur amino acids) and lysine were considered, according to their specific functional role in metabolic and physiological processes. For this purpose, the effects of the deviations between amino acid profiles of dietary and ideal protein (excess protein) on voluntary feed intake and growth performance were investigated, in relation to the most limiting amino acid.

Owing to its poor contribution to metabolic processes, lysine is a stable reference for expressing ratios between essential amino acids. Unlike lysine, dietary tryptophan interacts heavily and negatively with excess protein (large neutral amino acids), through brain serotonin dysfunction, in relation to depressed appetite and growth. In practice, the tryptophan / lysine ratio should not be considered as a constant. It should be corrected on the basis of a minimum ratio between tryptophan and large neutral amino acids of $4 \%$ in order to prevent an eventual risk of their excess in some dietary protein. In the case of threonine, when it is limiting, a positive interaction with non essential amino acids (glutamic acid) was reported. Dietary balance between methionine and cystine was re-evaluated in accordance with the recent data from literature. To conclude, the revised essential amino acid to lysine ratios for the growing pig were given.

HENRY Y, 1993. Affinement du concept de la protéine idéale pour le porc en croissance. INRA Prod. Anim., 6 (3), $199-212$ 